\title{
FORMATION OF TEACHERS' READINESS TO WORK IN AN INCLUSIVE EDUCATIONAL ENVIRONMENT
}

\author{
Bocheliuk V. Y., Panov M. S.
}

\section{INTRODUCTION}

Professional psychological and pedagogical activity in terms of educational inclusion does not mean a mechanical summation of professional tasks, knowledge, skills and abilities previously acquired by specialists to work in general and special (correctional) educational institutions. The changed educational space and educational environment involve the search for ways to solve an important and complex task of preparing teachers for a new synthetic type of professional activity. Actualization of this problem requires the development of modern ways and programs of teacher training to work with children with special educational needs in an inclusive educational environment.

The purpose of our proposed program is to prepare teachers to work in an inclusive educational environment.

Teacher training, namely the organization of the educational process, according to our program, was bipolar in nature. One of the «poles» of the educational process is theoretical training, the next - practical. This trajectory is built on the classical scheme of theoretical and practical training. Theoretical and practical aspects of providing professional competence of teachers involve the implementation of inclusive-oriented content of education on an integrative basis. Inclusive educational environment is a synergetic educational environment capable of selfimprovement and providing quality psychological and pedagogical support and meeting the individual educational needs of each child with special educational needs based on competence and professional cooperation ${ }^{12}$.

\section{Pedagogical conditions}

Interdependence and complementarity of organizational-pedagogical, content-pedagogical and procedural-pedagogical conditions forms a single

${ }^{1}$ Clough P., Corbett J. Theories of inclusive education : a student's guide. London : SAGE Publications Ltd, 2000. 200 p.

${ }^{2}$ Winzer M. A. From integration to inclusion: a history of special education in the 20th century. Washington, DC : Gallaudet University Press, 2009. 302 p. 
set of pedagogical conditions of the process of forming teachers' readiness to work in an inclusive educational environment, which includes:

1) Resource and scientific-methodical support of the process of formation of teachers' readiness to work in an inclusive educational environment;

2) Creation of a tolerant environment of the educational process based on the definition of the value-semantic content of education as a component of culture and motivation of future professionals to tolerant behavior by accepting tolerance as a value and norm of society;

3) Diagnostics and monitoring of the results of teachers' readiness to work in an inclusive educational environment.

\section{Implementation vectors}

Each pedagogical condition has implementation vectors, the most important of which are the following:

1.1. Providing preventive training and advanced training of teaching staff in the aspect of acquaintance with the essence, features, principles and values of inclusive education, as well as focusing the content of academic disciplines on positioning the ideas of inclusion and readiness of teachers to work in an inclusive educational environment. Forms of work with the teaching staff of higher education institutions can be educational seminars, methodical conferences and trainings.

1.2. Construction of a competency model of forming the readiness of teachers to work in an inclusive educational environment in terms of structural and functional analysis of professional and pedagogical activities in an inclusive educational space and subject-functional analysis of the positions of its participants. Structural and functional analysis of pedagogical activities in terms of educational inclusion allows establishing its component composition (diagnostic, design, organizational, communicative, reflective, prognostic components), the method of organization and relationship of components, as well as the functional purpose of each component.

1.3. Implementation of the competence approach in the formation of teachers' readiness to work in an inclusive educational environment as an educational effect involves determining the competence content of each of its structural components (cognitive, emotional-conative, communicative, reflexive), reflecting them in the content and organizational forms of higher education as well as preventive training of teaching staff to implement a competency-based approach in shaping the readiness of teachers to work in an inclusive educational environment. This training must be focused and is systemic.

1.4. Ensuring positive educational interference in the logic of the deductive approach, which is expressed in the designation of the position, 
semantic emphasis of educational material that defines the ideas, values and principles of inclusive education in the subject areas of all blocks of the curriculum. The basis of such educational interference is the observance of cyclical temporal (throughout the period of teacher training) and spatial (higher education institutions, places of pedagogical practices, participation in extracurricular activities, etc.) prolongation of the process of teachers' readiness to work in inclusive education environment determined by translational and evolutionary social and cultural change.

2.1. Creating and maintaining a tolerant environment in the educational process as a condition for implementing the principle of inclusiveness, which involves teachers to accept diversity («otherness») as a source of enrichment of communication and interaction, expanding perceptions of the world and implementing opportunities for support and assistance, as well as content and organizational variability educational process. Creating a tolerant educational environment goes beyond the educational institution and extends to the information activities of students, in which future professionals are involved in the volunteer movement. The basis for creating a tolerant environment is the subject-subject relations of the participants of the educational space, built on the acceptance of each other and the focus on the uniqueness of each. Didactic mechanisms for creating and maintaining a tolerant educational environment are methods of dialogue learning that help prevent situational anxiety and overcome fears of communication, discussion of pedagogical situations (cases), solving generalized professional tasks, the use of educational debates and other simulation teaching methods.

2.2. Creating an emotionally rich educational environment as a characteristic of the educational space of higher education institutions, aimed at stimulating the acceptance of future professionals of all subjects of inclusive education, as well as the intention to effectively communicate with them. Such work involves the extensive use of emotionally colored texts, movies and videos, which position the achievements and success of children and people with disabilities, creating figurative ideas and concepts about them.

3.1. Ensuring systematization and consistency in the formation of teachers' readiness to work in an inclusive educational environment, creating conditions for achieving the effect of «pedagogical resonance» through the variability of organizational forms, technologies and teaching methods, as well as extracurricular activities (involvement in volunteering, information campaigns, meetings with parents, etc.), which provide for purposeful and comprehensive formation of academic, professional and social-personal competencies that form the basis of the announced readiness.

3.2. Substantive interdependence of disciplines of the teacher training curriculum, which reflects the meanings, values of inclusive education, 
personal and pedagogical tolerance, which ensures the implementation of the «axiological-consolidating function of education».

This, firstly, involves the integration of theoretical, methodological, psychological, pedagogical and special knowledge through the study of disciplines «Fundamentals of education and upbringing of children with special needs», «Fundamentals of inclusive education», participation in trainings «Tolerant teacher», «Inclusive education: the essence, benefits and risks» and more. Secondly, it is necessary to ensure the translation of the ideas of inclusive education and the formation of teachers' readiness to work in an inclusive educational environment by considering certain issues of theory and practice of inclusive processes in the content of other disciplines of the curriculum. For example, «Philosophy» (the value of human life; tolerance as a way of thinking, communicating, interacting), «Economic Theory» (education and employment of people with disabilities), «Sociology» (accessibility of education for all), «Foreign language» (selection of texts that reveal the problems of discrimination in society and education, interaction in the general educational space, etc.) and more. Third, it is necessary to provide practical training for students in educational institutions that implement inclusive practices.

3.3. Complexity and variability of forms and means of forming teachers' readiness to work in an inclusive educational environment through the consistent inclusion of students in psychological and pedagogical activities, adequate to the current conditions of professional realization (development of a variable level system of tasks, solving professional tasks and pedagogical situations; performing tasks during pedagogical practice; participation in trainings, in the work of the resource center of inclusive education, in project activities; development of social interactive theater scenarios; participation in information campaigns on positioning ideas inclusive education, etc.). Extensive use of forms of work that allow students to form the competencies of collegial (team) style of activity, decisionmaking and their implementation in a multi-subject educational space (case technology, project method, etc.).

3.4. Use of incentives that increase teachers' satisfaction with the content and conditions of professional activity and reduce the subjective perception of the risk of change associated with inclusive education through the development of learning strategies based on an interdisciplinary approach. Psychological and pedagogical activity is essentially a managerial activity, which means the possibility of extrapolation of psychological models of work with risks to the educational environment. Such activities include work on prevention of pedagogical risks, as well as the development of anti-risk program based on the identification of risk factors, their analysis and 
assessment, risk response-planning, control and monitoring of risk minimization, risk management planning.

3.5. Diagnostic and methodological support of the process of forming teachers' readiness to work in an inclusive educational environment as a whole and its individual components on the basis of monitoring educational results, educational effects and providing them with the conditions of the educational process. The basis of such support is a criterion complex, which includes an assessment of the process of training psychological and pedagogical staff (pedagogical and socio-psychological aspects) and educational results (a set of competencies that determine the components of the announced readiness of future professionals).

The implementation of the proposed set of pedagogical conditions provides a systematic work both in content (achievement of educational results), in organizational aspects, coincides with the targets of professional psychological and pedagogical education, and allows future professionals to form a willingness to work in an inclusive educational environment inclusive readiness.

\section{Interactive exercises}

In order to determine the features of perceptions of children with special educational needs, interactive exercises were conducted with teachers at seminars. For example, the task of the «Bag of Associations» exercise is to identify associations that arise in young professionals when they talk about children with special educational needs. Thus, we wrote the phrase «child with special educational needs» on the board. They offered to write on the stickers the words associated with the above phrase and attach them to the «Bag of Associations». Each of them proposed his association, arguing it. We want to note, that the following associations predominated, in particular: wheelchair, dandruff, hearing aid, unfortunately, secrecy, not like everyone else, sadness, grief, self-doubt, loneliness, and so on.

The purpose of the exercise «Reflections on the lives of children with special educational needs» - to analyze the attitude of others to such children and express their views on this. We gave statements to subjects about children with special educational needs, for example: «These are little people who need help from the outside world»; «This is a great sorrow for the family»; "Such children need a tolerant attitude from the state»; «It is difficult for such children to adapt in society, because every minute they feel useless». As well as the following phrases: «Children who are unlucky in life, who are deprived of nature»; "Children with special educational needs should be considered as people like everyone else»; «These are children who by their existence, their presence bring up all of us»; «Along with them, we learn to empathize, be humane, tolerant, and so on. Then we discussed the 
statements. We divided the subjects into two groups, each of which advocated a positive or negative attitude towards children with special educational needs, proving to opponents which statement caused outrage and which they agreed with.

We used the exercise «Incomplete sentences» at the stage of consolidating knowledge about people with special educational needs; its essence was to find out the personal attitude to people with special educational needs from the point of view of teachers, the public, parents and children (experts chose the proposed roles at their discretion). Thus, we offered each of them a card with a sentence that they had to complete: «When I meet people with disabilities, I experience such feelings»; «When I see a child with special educational needs, I want...». As well as the following phrases: «I would like to help children with special educational needs because...»; "Children with special educational needs need...»; «To work with children with special educational needs, such qualities are needed...» and others. Then the experts commented on the composed sentences at will. Thus, using these exercises, we found out which personal attitudes towards people with special educational needs prevail among psychological and pedagogical specialists.

The topic «Pedagogy in the system of human sciences» training course «Pedagogy» of the content module «General principles of pedagogy» was supplemented by questions «Inclusive education as a model of social order: genesis, conceptual and terminological definitions, basic principles». Topic «Development, socialization and education of the individual» - the question «Inclusion - the strategy of international and Ukrainian law», the topic «The pedagogical process as a system and a holistic phenomenon». Regularities and principles of the pedagogical process - questions «Socio-humanistic function of inclusive education», «The role of parents in the implementation of inclusive education». Topic «Subject and main categories of didactics. The learning process, its structure. Different approaches to teaching» content module «Theory of education and training» was supplemented by «Different approaches to the implementation of inclusive education in Ukraine», and the content module «Management of pedagogical systems» was expanded by «Scientific and methodological foundations of professional cooperation of teachers in inclusive education».

In order to form professional and value orientations, solve communicative problems and problems related to inclusion, during the study course «Pedagogy» interactive methods were used, which were aimed at forming professional cooperation of future psychological and pedagogical professionals, for example: business game, round table, discussion, press conference, debate. 
At the seminars on the course «Pedagogy» at the stage of motivation of educational activities and in order to form communication tolerance specialists conducted exercises that taught them to work in a team in an inclusive educational environment. For example, during the exercise «Untangle the ball», they stood in a circle close to each other and stretched both hands to the center of the circle. On command, everyone tried to grab someone's hand with their hands, preferably the hand of a person who is away from you. When they joined their hands in pairs, we asked the experts to «untangle» without separating the hands, after which the question was asked: «What could have been done differently when performing the task?» During the discussion, the subjects realized that a friendly attitude to each other, tolerance and support for ideas expressed by other participants, help to quickly and efficiently perform the task.

In the content module, «Personality in activity and communication» of the training course «Psychology» the question «Peculiarities of mental development of children with special educational needs» was included in the plan of the topic «Personality». On the topic «Communication» - the question «Peculiarities of communication with children with special educational needs in an inclusive learning environment», «Culture of communication in the course of professional cooperation of a team of teachers in an inclusive educational environment». In each topic of the module "Cognitive activity of the person» questions concerning features of attention, imagination, perception, memory, thinking of children with special educational needs were considered. Before the seminars, they prepared reports, videos, in which they showed the comments of psychologists on the peculiarities of the mental development of children with special educational needs.

The formation of specialists' ability to see in each child personality, individuality, to be attentive to children's problems, to the culture of communication during professional cooperation in inclusive education took place in seminars in the process of interactive exercises and business games «Potato», «Be close», «Blind and guide» and others). For example, the purpose of the «Potato» exercise is to demonstrate in practice that all children, regardless of their special educational needs, are equal and at the same time unique. In the process of performing the exercise, specialists had to illustrate the uniqueness of each individual. We handed them potatoes, which they examined for one minute to find out in detail its «special» features. Then we mixed potatoes and gave subjects the task to find their potatoes and describe them. After the exercise was a discussion on the following questions: "Was it difficult to cope with the task? What skills and abilities needed to carry it out? (Observation, concentration, concentration, analytical skills, creative skills, ability to compare, distinguish, apply imagination, fantasy, flexibility of thinking). Which of these qualities are 
especially important in the interaction of teachers with children with special educational needs? Why?».

During the exercise «Being close», we asked experts to think about what is most important in their lives and imagine that all this is close. Then they had to write their feelings on a piece of paper. In discussing this situation, they concluded that it is probably also important for a child with special educational needs to be close to those who understand and support her, that everyone can become that person if they wish to do so.

The content module «General patterns of human development» of the course «Age Physiology» was supplemented by the topic «Children with special educational needs as a subject of inclusive education», during the study of which considered the nature, causes and classification of psychophysical development of children with special educational needs. In order to form basic knowledge and skills on this topic, the subjects prepared for seminars reports and abstracts on «Etiology and classification of mental retardation», «The role of hearing in human development», «Psychological and pedagogical characteristics of children with speech disorders», as well as videos about new methods of treatment and prevention of psychophysical disorders.

During the seminars, we paid special attention to interactive exercises, which helped to design a specific problem situation that involved empathy for children with special educational needs. For example, during the exercise «Imagine the situation» experts were asked to imagine that they, having cerebral palsy (their movements, balance and body position are disturbed, it is difficult to move), got on the bus and heard ridicule in his address, and in that place where you could sit, sat a little girl. Experts, using a «brainstorming», described their feelings about this situation. We asked them such questions as: «Was it hard on the soul? Has your attitude to the world around you changed? Did the little girl do the right thing in this situation? Why did the girl do that?» Then there was a discussion of the problem on the following questions: «Is it difficult to imagine yourself as a person with disabilities? Has your attitude towards such people changed?»

During the exercise «Let's go blind», we placed the subjects in pairs or threes. One was blindfolded; the other helped to overcome the route through the audience. Then the roles changed.

The purpose of the above exercises is to form in specialists the ability to feel in the place of people with special educational needs who are constantly experiencing certain problems due to their peculiarity.

The content module «General principles of pedagogical activity» of the discipline «Introduction to the specialty» was expanded by the topic «The role of teachers in the implementation of inclusive education», which included questions: advice to teachers who teach or raise children with special educational needs; teacher as a leader of change in an institution with 
inclusive education. The topic «Fundamentals of pedagogical activity and requirements for the teacher's personality» is supplemented by questions: features of pedagogical activity with children with special educational needs in the conditions of inclusive education and upbringing; qualification responsibilities of specialists in an inclusive educational environment; pedagogical activity of the teaching team of teachers in the conditions of inclusive educational environment. The essence of these issues was considered taking into account the specifics of each of the specialties.

At the seminar, the issue «Awareness of the role of the teacher in working with children with special educational needs in an inclusive education and upbringing» was considered in the form of a business game «Dots». The game involved cooperative training of specialists in pairs. One subject acted as a teacher and, imagining an image, drew it on a sheet of paper in the form of dots. The second acted as a child with special educational needs, whose task was to connect the dots, to try to recreate the intended image. The tasks were performed non-verbally, and after its completion, the intended images were discussed. At the end of the discussion, we asked the questions for reflection: «Did the child with special educational needs manage to reproduce your idea? What difficulties did you have during the task?» The researchers concluded that if to reflect the idea in the form of a contour, the child with special educational needs would be easier to complete the task and the success of its work would be guaranteed. Thus, the quality of education and upbringing of children with special educational needs depends entirely on the quality of support from their teachers.

The formation of the ability to provide a favorable atmosphere in an inclusive educational environment, to establish strong contact with participants in the educational process and to adapt to the specifics of each contributed, for example, such tasks: make a list of skills of psychological and pedagogical professionals who work with children with special educational needs and identify those who are underdeveloped; choose the most effective from the general pedagogical principles of inclusive class / group leadership; develop a code of ethics for communication between students and teachers with children with special educational needs.

The ability to work in a team to perform the functional responsibilities of teachers for effective psychological and pedagogical support of children with special educational needs in an inclusive educational environment, the subjects worked on a lesson built in the form of a pedagogical council. They needed to be divided into micro groups and choose the roles of participants in the psychological and pedagogical support of children with special educational needs in an inclusive education. For example, the first micro group is the administration of an educational institution; the second - teachers (educators or teachers), the third - psychologists, the fourth - social educators. The task 
of micro groups is to make a list of functional responsibilities that must be performed by each of these subjects of the educational process in working with children with special educational needs in an inclusive educational environment. One of the studied micro groups presented completed tasks, which discussed all group members (teachers' council members). Following the results of the pedagogical council, a decision wasmade to approve the professional responsibilities of psychological and pedagogical specialists of educational institutions in working with children with special educational needs. This approach to the organization of the educational process contributed to the formation of their ability to differentiate the areas of activity of the above specialists in order to avoid overload, duplication of their services. This, in turn, increases the level of mobility of the team of specialists, as well as the degree of its adaptation to unusual situations. The division of responsibilities (correctional and developmental assistance) allows each member of the team to feel their importance, which is extremely important, because the team is a community of «equals».

The formation of cultural values inherent in an inclusive society and skills of professional cooperation in an inclusive educational environment was facilitated by training sessions "Value and uniqueness of everyone», «Different opportunities - equal rights», «Personal qualities and skills of psychological and pedagogical specialist in working with children with special educational needs», organized for the subjects.

For the formation of personal values, empathy, charity, responsibility for children with special educational needs, humanistic orientation on social development, their specialists were involved in organizing and participating in art festivals held for such children, in particular: «I believe I can!», «Creativity without borders», social programs «Volunteer», «Without barriers», charity events «Give children a holiday», «Fabulous opening», etc.

Thus, the use of system in the planning and organization of the educational process based on a combined approach contributed to the formation of specialists in social and communicative-informational competencies.

The process of formation of psychological and pedagogical competence involved mastering the studied effective pedagogical technologies in the context of inclusive education and acquaintance with the organizational and methodological conditions of their use in the process of professional cooperation in an inclusive educational environment. Implemented the tasks with the help of new training courses «Differentiated teaching in an inclusive classroom», «Individual assessment of academic achievement of students with special educational needs in an inclusive classroom». In the course of studying new disciplines, attention was focused on the formation of a conscious understanding by specialists that in order to implement 
inclusion in an educational institution, psychological and pedagogical staff must change. This means that they must: accept and understand the new educational paradigm, new ways and forms of organizing the educational process in an inclusive educational environment; learn to develop a new curriculum of educational, correctional and developmental processes of inclusive education; master effective pedagogical technologies of teaching and education, methods of differentiated teaching and personality-oriented learning depending on the individual needs of children with special educational needs; to arm themselves with knowledge, skills and abilities to assess the educational achievements of preschoolers and primary school students with special educational needs; to form an idea of professional cooperation of teachers as a condition for the implementation of differentiated teaching and assessment of educational achievements of children with special educational needs in an inclusive educational environment. Therefore, teachers should be able to create a single system of education based on optimal methods for all children, in which the teaching staff of the educational institution would perform a common task - to support all children and help them prepare for independent living.

The next stage of increasing professional cooperation of teachers was to acquire their knowledge, skills and abilities to develop an individual program for the development of a child with special educational needs, who learns in an inclusive educational environment. Here is an example of a lesson-consultation.

\section{Individual development program}

We asked the specialists to make an individual development program for a preschool child with mental retardation, which is brought up in an inclusive group. At first, the specialists were acquainted with the general information and psychodiagnostic report on the child. Then, based on psychodiagnostic examination, they ascertained the level of her mental development and made suggestions for the correction of her mental processes (attention, perception, thinking, memory) and the use of effective psychological technologies in inclusive education. These included: technologies for relaxation of the respiratory system and muscle relaxation, exercises-games for the correction of attention («Teaching a pattern», «Find a mistake», «Count objects», «Nonsense»), perception («Know by touch», «Layouts into groups», «Color distinction», «Which geometric shapes make up a picture», «Determining the size by touch»), thinking («Talking pictures» (pictography), «Classification of geometric shapes», «Compositions of letters» word», «Composing a story based on a series of pictures», «Find the same objects»), memory («Repeat the word», «Remember and tell», «Does this happen?»). Taking into account the 
recommendations of psychologists on the formation of mental processes in the child, educators determined the forms of work (for example, at the initial stage of individual work, then alternation of individual and group), then offered a game of learning and effective pedagogical technologies to improve cognitive and speech activity (bioenergy plastics, logarithmic, puppet therapy, etc.) using the technology of differentiated teaching in an inclusive educational environment.

The final stage of the project was its presentation and group discussion of teaching skills. According to experts, project work provides an opportunity for all children in an inclusive class: to master basic skills and fundamental processes (reading, writing, speaking, numbers) and learn to apply them in practice; join active knowledge of the world in various activities; to express their desires, interests, abilities, problems in the process of cooperative activity; to form skills of search and research activity; to develop critical, creative thinking and creative abilities; to form tolerant communication, friendliness in relations with a diverse team of children and teachers; regulate their behavior and evaluate their own actions. The researchers concluded that project activities make learning interesting and meaningful and the process of acquiring knowledge - easier and more accessible.

In order to determine in the course of experimental activities the current level of readiness of teachers to work in an inclusive educational environment and to analyze the results of the formative experiment was diagnosed.

In order to diagnose the levels of formation of the studied quality, the respondents of the control and experimental groups were offered the same questionnaire that was used at the initial stage of the formative experiment.

Implementation of the program of forming the readiness of teachers to work in an inclusive educational environment was carried out in the educational process of higher education institution in Zaporozhye («Zaporizhzhia Polytechnic» National University). The developed materials were implemented in parallel in four training courses for future specialists. In order to determine the reliability of the results of our study, we determined the F-criterion for the experimental groups (empirical criterion) and compared with the theoretical F-criterion, the numerical values of which are reflected in the tables developed by A. Kiveralg ${ }^{3}$.

We determined the F-criterion by the formula of A. Kiveralg:

$$
F_{\text {emp }}=\frac{\sigma_{1}^{2}}{\sigma_{2}^{2}},
$$

3 Кыверялг А. А. Методы исследования в профессиональной педагогике. Таллинн : Валгус, 1980. 335 с. 
where $\sigma_{1}^{2}-$ Variance at the initial stage of determining the levels of readiness of teachers of future professionals to work in an inclusive educational environment; $\sigma_{2}^{2}-$ Variance in the final control of the effectiveness of the formation of the readiness of teachers of future professionals to work in an inclusive educational environment at the final stage of the experiment.

The variance is determined by the formula:

$$
\sigma^{2}=\frac{\sum f\left(x_{i}-\bar{x}\right)^{2}}{N}
$$

where $f-$ the number of students whose grade 5, 4, 3, 2 indicates, respectively, high, sufficient, satisfactory and low levels of readiness of teachers of future professionals to work in an inclusive educational environment; $\left(x_{i}-\bar{x}\right)$ - The difference between the individual values of the estimates $(5,4,3,2)$ and the value of the average for a particular group and stage of control;

$\mathrm{N}$ - The number of students in those categories of groups (control or experimental), where the variance is calculated.

Femp-KG with a value of 1.06 is beyond probability, so we believe that a slight increase in the level of readiness of teachers of future professionals to work in an inclusive educational environment, who studied in control groups, is associated with the traditional learning process.

Therefore, it can be argued that the effectiveness of the formation of the readiness of teachers of future professionals to work in an inclusive educational environment depends on the purposeful application of the proposed program.

The control groups included 112 students, the experimental groups 104 applicants.

In order to analyze the results of the experimental study, we recorded the dynamics of changes in the levels of readiness to work in an inclusive educational environment (table 1). 
Table 1

The results of the formative stage of the experimental study

\begin{tabular}{|c|c|c|c|c|c|c|c|c|c|c|c|}
\hline \multirow{3}{*}{$\begin{array}{l}\mathbf{C} \\
\mathbf{o} \\
\mathbf{u} \\
\mathbf{r} \\
\mathrm{s} \\
\mathrm{e}\end{array}$} & \multirow{3}{*}{ G. } & \multirow{3}{*}{$\begin{array}{c}\text { Sta } \\
\text { ge } \\
\text { cont } \\
\text { rol }\end{array}$} & \multicolumn{9}{|c|}{$\begin{array}{l}\text { Levels of readiness to form teachers' readiness } \\
\text { to work in an inclusive educational environment }\end{array}$} \\
\hline & & & \multicolumn{2}{|c|}{$\begin{array}{c}\text { High } \\
(5 \text { points })\end{array}$} & \multicolumn{2}{|c|}{$\begin{array}{l}\text { Sufficient } \\
\text { (4 points) }\end{array}$} & \multicolumn{2}{|c|}{$\begin{array}{l}\text { Satisfactory } \\
\text { (3 points) }\end{array}$} & \multicolumn{2}{|c|}{$\begin{array}{c}\text { Low } \\
\text { (2 points) }\end{array}$} & \multirow{2}{*}{$\begin{array}{c}\text { aver } \\
\text { age }\end{array}$} \\
\hline & & & КС & $\%$ & КС & $\%$ & кС & $\%$ & КС & $\%$ & \\
\hline \multirow{4}{*}{ I } & CG/ & IC & 2 & 1,79 & 40 & 35,71 & 66 & 58,93 & 4 & 3,57 & 3,36 \\
\hline & $\begin{array}{c}112 \\
\text { s. }\end{array}$ & FC & 3 & 2,68 & 42 & 37,5 & 65 & 58,03 & 2 & 1,79 & 3,41 \\
\hline & EG/ & IC & 2 & 1,92 & 36 & 34,62 & 63 & $\begin{array}{c}60,58 \\
\end{array}$ & 3 & 2,88 & 3,36 \\
\hline & $\begin{array}{c}104 \\
\text { s. }\end{array}$ & FC & 9 & $\begin{array}{l}8,65 \\
\end{array}$ & 43 & 41,35 & 52 & 50,0 & 0 & 0 & 3,59 \\
\hline \multirow{4}{*}{ II } & CG/ & IC & 2 & 1,9 & 38 & 36,2 & 63 & 60,0 & 2 & 1,9 & 3,38 \\
\hline & $\begin{array}{c}105 \\
\text { s. }\end{array}$ & FC & 3 & 2,85 & 40 & 38,1 & 61 & 58,1 & 1 & 0,95 & 3,4 \\
\hline & EG/ & IC & 7 & 7,0 & 40 & 40,0 & 53 & 53,0 & 0 & 0 & 3,54 \\
\hline & $\begin{array}{c}100 \\
\text { s. }\end{array}$ & FC & 11 & 11,0 & 44 & 44,0 & 45 & 45,0 & 0 & 0 & 3,66 \\
\hline \multirow{4}{*}{ III } & CG/ & IC & 1 & 1,02 & 38 & 38,78 & 58 & 59,18 & 1 & 1,02 & 3,4 \\
\hline & $98 \mathrm{~s}$. & FC & 2 & 2,04 & 39 & 39,8 & 57 & 58,16 & 0 & 0 & 3,48 \\
\hline & EG/ & IC & 7 & 7,37 & 39 & 41,05 & 49 & 51,58 & 0 & 0 & 3,56 \\
\hline & $95 \mathrm{~s}$. & FC & 13 & 13,68 & 43 & 45,26 & 39 & 41,05 & 0 & 0 & 3,73 \\
\hline \multirow{4}{*}{ IV } & CG/ & IC & 2 & 2,13 & 33 & 35,11 & 59 & 62,76 & 0 & 0 & 3,43 \\
\hline & $94 \mathrm{~s}$. & FC & 5 & 5,32 & 35 & 37,23 & 54 & 57,45 & 0 & 0 & 3,48 \\
\hline & EG/ & IC & 11 & 11,96 & 41 & 44,56 & 40 & 43,48 & 0 & 0 & 3,69 \\
\hline & $92 \mathrm{~s}$. & FC & 19 & 20,65 & 49 & 53,26 & 24 & 26,09 & 0 & 0 & 3,95 \\
\hline
\end{tabular}

Legend: IC - input control; FC - final control; $A I$ - the average indicator of teachers' readiness to work in an inclusive educational environment

\section{CONCLUSIONS}

The results allow us to conclude that despite the fact that the number of students in control and experimental groups changed every year, the effectiveness of teachers' readiness to work in an inclusive educational environment, but in experimental groups was determined by better performance at all levels than in control groups. We compared the dynamics of the averages, which was observed in the control group and the Experimental group throughout the formative stage of the experimental study.

It was found that the average readiness of teachers to work in an inclusive educational environment in the control and experimental groups has the same value -3.36 points. After graduation in the first year in the control group, this figure increased to 3.41 points ( 0.05 points), and in the experimental group - to 3.59 points ( 0.23 points), which is 0.18 points more than in the control groups.

During the formative stage of the experimental study, there was a progressive dynamics of improving the readiness of teachers of future professionals to work in an inclusive educational environment, who studied in control and experimental groups, which is reflected in table 2. 
Table 2

The results of the formative stage of the experimental study

\begin{tabular}{|c|c|c|c|c|c|c|c|c|c|c|}
\hline \multirow{3}{*}{$\begin{array}{c}\mathbf{G} \\
\mathbf{r} \\
\mathbf{o} \\
\mathbf{u} \\
\mathbf{p} \\
\mathbf{S}\end{array}$} & \multirow{3}{*}{$\begin{array}{l}\text { Stage } \\
\text { control }\end{array}$} & \multicolumn{9}{|c|}{$\begin{array}{l}\text { Levels of readiness to form teachers' readiness } \\
\text { to work in an inclusive educational environment }\end{array}$} \\
\hline & & \multicolumn{2}{|c|}{$\begin{array}{c}\text { High } \\
(5 \text { points })\end{array}$} & \multicolumn{2}{|c|}{$\begin{array}{l}\text { Sufficient } \\
(4 \text { points })\end{array}$} & \multicolumn{2}{|c|}{$\begin{array}{l}\text { Satisfactory } \\
\text { ( } 3 \text { points) }\end{array}$} & \multicolumn{2}{|c|}{$\begin{array}{c}\text { Low } \\
(2 \text { points }) \\
\end{array}$} & \multirow{2}{*}{ Average } \\
\hline & & КС & $\%$ & КС & $\%$ & КС & $\%$ & кС & $\%$ & \\
\hline \multirow[t]{2}{*}{ CG } & $\mathrm{IC}-112 \mathrm{~s}$ & 2 & 1,79 & 40 & 35,71 & 66 & 58,93 & 4 & 3,57 & 3,36 \\
\hline & $\mathrm{AI}-94 \mathrm{~s}$. & 5 & 5,32 & 35 & 37,23 & 54 & 57,45 & 0 & 0 & 3,48 \\
\hline \multirow[t]{2}{*}{ EG } & IC $-104 \mathrm{~s}$. & 2 & 1,92 & 36 & 34,62 & 63 & 60,58 & 3 & 2,88 & 3,36 \\
\hline & $\mathrm{AI}-92 \mathrm{~s}$ & 19 & 20,65 & 49 & 53,26 & 24 & 26,09 & 0 & 0 & 3,95 \\
\hline
\end{tabular}

Data analysis allows us to conclude about the effectiveness of our experimental program and its positive impact on the formation of readiness of teachers of future professionals to work in an inclusive educational environment.

In order to determine the reliability of the results of our study, we determined the F-criterion for the experimental groups (empirical criterion) and compared with the theoretical F-criterion, the numerical values of which are reflected in the tables developed by A. Kiveralg.

We determined the F-criterion by the formula of A. Kiveralg:

$$
F_{\text {emp }}=\frac{\sigma_{1}^{2}}{\sigma_{2}{ }^{2}},
$$

where $\sigma_{1}^{2}-$ Variance at the initial stage of determining the levels of readiness of teachers of future professionals to work in an inclusive educational environment;

$\sigma_{2}{ }^{2}$ - Variance in the final control of the effectiveness of the formation of the readiness of teachers of future professionals to work in an inclusive educational environment at the final stage of the experiment.

The variance is determined by the formula:

$$
\sigma^{2}=\frac{\sum f\left(x_{i}-\bar{x}\right)^{2}}{N}
$$

where $f$ - the number of students whose grade 5, 4, 3, 2 indicates, respectively, high, sufficient, satisfactory and low levels of readiness of teachers of future professionals to work in an inclusive educational environment;

$\left(x_{i}-\bar{x}\right)$ - The difference between the individual values of the estimates $(5,4,3,2)$ and the value of the average for a particular group and stage of control;

$\mathrm{N}$ - The number of students in those categories of groups (control or experimental), where the variance is calculated. 
Femp-KG with a value of 1.06 is beyond probability, so we believe that a slight increase in the level of readiness of teachers of future professionals to work in an inclusive educational environment, who studied in control groups, is associated with the traditional learning process.

Therefore, it can be argued that the effectiveness of the formation of the readiness of teachers of future professionals to work in an inclusive educational environment depends on the purposeful application of the proposed program.

\section{SUMMARY}

The article is devoted to the conditions of forming the readiness of teachers to work in an inclusive educational environment. The purpose of the article is to offer a program to prepare teachers to work in an inclusive educational environment. Particular attention is paid to the organization of the educational process, which according to the proposed program is bipolar in nature. One of the «poles» of the educational process is theoretical training, the next - practical. This trajectory is built on the classical scheme of theoretical and practical training. Theoretical and practical aspects of the formation of professional competence of teachers involve the implementation of inclusive-oriented content of education on an integrative basis. It also outlines a set of pedagogical conditions for the process of forming teachers' readiness to work in an inclusive educational environment. Each pedagogical condition has its own vectors of implementation. The article also provides exercises and seminars on the formation of teachers' readiness to work in an inclusive educational environment. The purpose of the exercises is to form in specialists the ability to feel in the place of people with special educational needs who are constantly experiencing certain problems due to their peculiarity. In order to determine the reliability of the results of our study, we determined the F-criterion for experimental groups (empirical criterion) and compared with the theoretical F-criterion developed by A. Kiveralg. In order to analyze the results of the experimental study, the dynamics of changes in the indicators of the levels of formation of readiness for work in an inclusive educational environment was recorded. Data analysis allows us to conclude about the effectiveness of our experimental program and its positive impact on the formation of readiness of teachers of future professionals to work in an inclusive educational environment. Thus, it can be argued that the effectiveness of the formation of readiness of teachers of future professionals to work in an inclusive educational environment depends on the purposeful application of the proposed program. 


\section{REFERENCES}

1. Кыверялг А. А. Методы исследования в профессиональной педагогике. Таллинн : Валгус, 1980. 335 с.

2. Clough P., Corbett J. Theories of inclusive education : a student's guide. London : SAGE Publications Ltd, 2000. 200 p.

3. Winzer M. A. From integration to inclusion: a history of special education in the 20th century. Washington, DC : Gallaudet University Press, 2009. 302 p.

\section{Information about the authors:} Bocheliuk V. Y.,

Doctor of Sciences in Psychology, Professor, Professor at the Department of Social Work and Psychology «Zaporizhzhia Polytechnic» National University 64, Zhukovsky str., Zaporizhia, 69063, Ukraine

Panov M. S.,

Doctor of Sciences in Psychology, Associate Professor, Associate Professor at the Department of Special Pedagogy and Special Psychology

Municipal Institution of Higher Education "Khortytsia National Educational and Rehabilitational Academy" of Zaporizhzhia Regional Council 59, Naukove Mistechko str., Zaporizhia, 69017, Ukraine 